\title{
Erratum to: Age-Related Differences in Response to Music-Evoked Emotion Among Children and Adolescents with Autism Spectrum Disorders
}

\author{
K. G. Stephenson ${ }^{1}$ E. M. Quintin ${ }^{2}$ M. South ${ }^{3}$
}

Published online: 23 December 2015

(c) Springer Science+Business Media New York 2015

\section{Erratum to: J Autism Dev Disord DOI 10.1007/s10803-015-2624-1}

The original version of this article unfortunately contained errors in the reference list and text citation. Two entries are missing in the reference list.

The authors inadvertently failed to cite the work of Allen et al. (2013), showing physiological effects of emotional music in adults with autism spectrum disorders, and Heaton et al. (2008), highlighting the importance of language development in musical understanding. The complete references are given below.

\section{References}

Allen, R., Davis, R., \& Hill, E. (2013). The effects of autism and alexithymia on physiological and verbal responsiveness to music. Journal of Autism and Developmental Disorders, 43(2), 432-444. doi:10.1007/s10803-012-1587-8.

Heaton, P., Allen, R., Williams, K., Cummins, O., \& Happé, F. (2008). Do social and cognitive deficits curtail musical understanding? Evidence from autism and Down syndrome. British Journal of Developmental Psychology, 26(2), 171-182. doi:10. 1348/026151007X206776.

The online version of the original article can be found under doi:10.1007/s10803-015-2624-1.

K. G. Stephenson

kevingstephenson@gmail.com

1 Department of Psychology, Brigham Young University, 245 TLRB, Provo, UT 84602, USA

2 Educational and Counselling Psychology Department, McGill University, Montréal, QC, Canada

3 Department of Psychology, Neuroscience Center, Brigham Young University, Provo, UT, USA 